\title{
An assessment of prescribing skills among dental students in the eastern province, Saudi Arabia, University of Dammam
}

\section{Hassan Ayesh Alali*, Hassan Abdulmohsen Alali, Abdullrahman Abdullah Alghamdi, Abdulaziz Ibrahim Al Ali, Ahmed Hassan Alkhalaf, Balgis Jaffar}

College of Dentistry, Imam Abdulrahman Bin Faisal University, Dammam, Saudi Arabia

Received: 19 August 2018

Accepted: 06 September 2018

\section{*Correspondence:}

Dr. Hassan Ayesh Alali,

E-mail: dr.hassan.alali@hotmail.com

Copyright: ( ) the author(s), publisher and licensee Medip Academy. This is an open-access article distributed under the terms of the Creative Commons Attribution Non-Commercial License, which permits unrestricted non-commercial use, distribution, and reproduction in any medium, provided the original work is properly cited.

\begin{abstract}
Background: The objectives of the study were to assess knowledge and prescription skills of medications among dental student in Dammam University and evaluate the efficiency of an online application in improving their knowledge.

Methods: A cross sectional pre-post study was conducted, a total of 96 students from 4th year to interns were enrolled. A formulated questionnaire was distributed to the students. An application that contained the most common drugs used in dentistry was made by the research team with help of the IT department and then launched. The same questionnaire was distributed again after one month from the time they got the application to evaluate its efficiency.

Results: Overall knowledge about medications was poor. Fifth year students reported better knowledge than their colleagues. All students have better knowledge about antibiotics compared to other drugs. Overall knowledge about therapeutic agents improved significantly after the web application $(\mathrm{p}<0.001)$.

Conclusions: Students have poor knowledge about medications. Using technology is an effective way to improve prescribing skill among dental students.
\end{abstract}

Keywords: Dental students, Drugs prescription, Pharmacology

\section{INTRODUCTION}

Prescription of medications is an important part of the treatment process in the medical and dental field. Medications are used to enhance the healing process after some surgical procedures in order to improve patients' life. A lot of diseases can be controlled by medications and every physician and dentist should be accurate and know what the best choice for the particular situation. Almost all medications have an adverse effect and some of them can be lethal.

Such a problem does exist among most of the undergraduates as documented internationally by many studies. ${ }^{1-4}$ One of which has concluded that the common error students have made, was related to drug posology
(74.2\%). Followed by improperly filled prescriptions $(10.7 \%) .{ }^{1}$ Another study by the Centers for Disease Control and Prevention (CDC) concluded that many Americans were prescribed medications without the patients being aware of other evidence-based treatments that might work better for them. ${ }^{5}$

Pre-graduate dental students in the University of Dammam take two pharmacology courses during their twelve-semesters program in the pre and clinical phases in which they are supposed to acquire the skills of accurately prescribing drugs. However, in the pre-clinical phase, particularly in the fifth level, the course aims to deliver the basics of pharmacology in the form of pharmacokinetics, pharmacodynamics, the main categories of drugs and their respective side effects which 
is more theoretical rather than the more needed practical part in the field of dental practice. Dental students would have to wait till the tenth level to have the second pharmacology course which is more practical in addition to studying the common drugs in dental practice. Since the clinical phase starts in the seventh semester, students wouldn't be prepared to actively and effectively prescribe drugs to patients whenever it is needed. Instead, this is usually done by faculty members with the students trying to follow their lead and gain their experience. Some students might even seek help from their senior colleagues. Being students we noticed that we lack the experience in prescribing medications to patients, and this could have serious impact on our patients in many ways, starting from prolongation of treatment plan, increasing healthcare cost, or even the exacerbation of the present illness. ${ }^{6}$ Some students think that their prescribing skills will improve after graduation but some researches, according the World Health Organization, have indicated that even though the general experience might get improved, the prescribing skills did not improve significantly. ${ }^{7}$

The number of dental colleges is increasing in the country; to our knowledge this area was not investigated before in the Kingdom. So this study aims to assess the knowledge and prescribing skills among dental students in the University of Dammam and to evaluate the efficiency of an online application in improving their knowledge and skills.

\section{METHODS}

This is a cross-sectional pre-post study with a consecutive sample. Ethical approval was received prior to the study (EA 2014, 021) from the college Research Review Board. A total of 96 dental students from College of Dentistry, university of Dammam (COD-UOD) from 4th year to interns were included. This was carried out in the CODUOD during the period of January 2015 to June 2015. A self-administered structured questionnaire was developed by the research team for the study purposes. Information of the questionnaire was collected through 2 ways:

1) Faculty members of King Fahad staff (through emails) about the most common prescribed drugs by them in a categorized manner, such as the most commonly prescribed analgesics, antibiotics, antifungals, antivirals, sedatives, drugs for pregnant female patients, and if they prescribe any preoperative medications for patients that are medically compromised or anxious.

2) Information from "Pharmacology and Therapeutics for Dentistry" a well-known dental medication dictionary by Yagiela. ${ }^{7}$

All collected information was checked and evaluated by faculty member of the pharmacology division in the college. As a result, a questionnaire with 27 closed ended-questions was prepared. The questionnaire was divided into two sections. The first section included demographic information in addition to general information such as how many pharmacology course(s) he/she has finished, what is the specialty of the teacher that is/was assigned to the course content (whether he/she was a dentist, pharmacist or a physician) in addition to their source of information or references while prescribing medications in clinical settings.

The second section of the questionnaire assessed students' knowledge about the mostly used and prescribed drugs in dentistry (referring to the faculty responses and Yagiela textbook) with sub-sections divided as follows: antibiotics, anti-fungal, anti-viral, analgesics, and sedatives. Each sub-section asked about whether the mentioned category was covered in the course or not, whether the student does prescribe this type of medication or not, along with questions about the objective of prescribing this category, dosage and frequency, most common side effect/s, contra-indications, drugs interactions, FDA pregnancy category of a specific drug, sub-categorization (if any), effectiveness and over the counter availability.

Dependent variable of the study was knowledge expressed as score per section (antibiotic, antifungal, etc.) and the overall score. Independent variables of the study were: level of the student and their source of information. Demographic factors such as age and gender were not included in the study; as only 14 were females and age was expressed as the student's study level.

Before the actual data collection, a pilot test was carried $(n=26)$ to check the reliability and validity of the questionnaire. Pilot data were entered into excel sheet by research team and sent to college statistician for analysis.

\section{Phase I}

Distribution of the questionnaire by research team to college students in lecture rooms during working hours to ensure maximum response; permission was obtained from teaching staff to distribute the questionnaire immediately after they finish their lectures. A user friendly application designed by the research team and university IT department was launched to provide a trusted evidence based reference following the WHO's guide to good prescribing. ${ }^{7,8}$ The program delivered focused information that relates to clinical prescribing skills. The information provided in the application was checked and revised by the pharmacology staff members. The application covered the most commonly used drugs in dental field and provided all needed information for the user that would help him/her in writing prescriptions. The application was delivered to the contributors using the official University emails and aided by social media to ensure its popularity.

\section{Phase II}

The same questionnaire was distributed after one month from launching the application to the same participants 
(only those who filled the previous one was permitted to participate) to test the efficacy of the application in improving their prescription skills.

Some questions from the pre-questionnaire were removed to avoid repetition. On the other hand, some questions were added to evaluate the web-application; such as if the student found it helpful, easy to use, will refer to it when prescribing medications and if he/she will recommend it to others.

Again data were entered in excel sheet, SPSS used for data analysis and comparison made before and after the application. The assessments of students' prescribing skills were measured in terms of overall scores (Max 27 scores). Answers were categorized into poor, moderate and good depending on the number of correct answers. The results of scores were presented into mean and standard deviation. Analysis of variance (ANOVA) was performed to compare the scores among four levels of the dentists. $\mathrm{P}<0.05$ was considered statistically significant.

\section{RESULTS}

\section{Pilot study}

A pilot study was carried to assess the validity and reliability of the questionnaire; 26 questionnaires were distributed among students from all grades that were later included in the study (4th to 6th grades and interns). From all the 26 distributed questionnaires 6 responded from 4th year, 15 from 5 th year, 3 from 6 th year and 2 were interns.

Data were entered into excel sheet and sent to biostatistician for analysis. The reliability of the questionnaire was 0.5 . In order to improve the validity some questions were modified and others were deleted; as such the reliability was improved to 0.7 .

\section{Actual study}

Out of 120 questionnaires distributed only 96 students filled the questionnaire (response rate was $80 \%$ ). Out of those $49(50 \%)$ students were from 4th year, $27(28 \%)$ students were from $5^{\text {th }}$ year, $14(15 \%)$ students were from 6 th year and $6(7 \%)$ were interns.

Age of the participants was in the range of 21-25 years; the majority were males $(n=82) 85.4 \%$ and only $(n=14)$ $14.6 \%$ were females.

All pharmacology courses to all years were taught by pharmacists.

Table 1: Comparison of knowledge sub-scores between different study levels before the application.

\begin{tabular}{|c|c|c|c|c|}
\hline Dependent variables & (I) Level & (J) Level & Mean difference (I-J) & $P$ value \\
\hline \multirow{12}{*}{$\begin{array}{l}\text { Score part-1 } \\
\text { (Antibiotics) }\end{array}$} & \multirow{3}{*}{ 4th year } & 5th year & $-2.56308^{*}$ & 0.000 \\
\hline & & 6 th year & -0.85429 & 0.168 \\
\hline & & Intern & -0.30667 & 0.954 \\
\hline & \multirow{3}{*}{5 th year } & 4th year & $2.56308^{*}$ & 0.000 \\
\hline & & 6 th year & $1.70879^{*}$ & 0.002 \\
\hline & & Intern & $2.25641^{*}$ & 0.002 \\
\hline & \multirow{3}{*}{ 6th year } & 4th year & 0.85429 & 0.168 \\
\hline & & 5 th year & $-1.70879^{*}$ & 0.002 \\
\hline & & Intern & 0.54762 & 0.842 \\
\hline & \multirow{3}{*}{ Intern } & 4th year & 0.30667 & 0.954 \\
\hline & & 5 th year & $-2.25641^{*}$ & 0.002 \\
\hline & & 6th year & -0.54762 & 0.842 \\
\hline \multirow{12}{*}{$\begin{array}{l}\text { Score part-2 } \\
\text { (Antifungal) }\end{array}$} & \multirow{3}{*}{ 4th year } & 5 th year & $-0.90000^{*}$ & 0.001 \\
\hline & & 6th year & -0.18571 & 0.917 \\
\hline & & Intern & $-1.56667^{*}$ & 0.001 \\
\hline & \multirow{3}{*}{5 th year } & 4th year & $0.90000^{*}$ & 0.001 \\
\hline & & 6th year & 0.71429 & 0.115 \\
\hline & & Intern & -0.66667 & 0.416 \\
\hline & \multirow{3}{*}{6 th year } & 4 th year & 0.18571 & 0.917 \\
\hline & & 5 th year & -0.71429 & 0.115 \\
\hline & & Intern & $-1.38095^{*}$ & 0.020 \\
\hline & \multirow{3}{*}{ Intern } & 4th year & $1.56667^{*}$ & 0.001 \\
\hline & & 5th year & 0.66667 & 0.416 \\
\hline & & 6th year & $1.38095^{*}$ & 0.020 \\
\hline
\end{tabular}




\begin{tabular}{|c|c|c|c|c|}
\hline Dependent variables & (I) Level & (J) Level & Mean difference (I-J) & P value \\
\hline \multirow{12}{*}{$\begin{array}{l}\text { Score part-3 } \\
\text { (Antiviral) }\end{array}$} & \multirow{3}{*}{ 4th year } & 5th year & -0.61846 & 0.061 \\
\hline & & 6th year & -0.52643 & 0.315 \\
\hline & & Intern & -0.70500 & 0.373 \\
\hline & \multirow{3}{*}{ 5th year } & 4 th year & 0.61846 & 0.061 \\
\hline & & 6th year & 0.09203 & 0.993 \\
\hline & & Intern & -0.08654 & 0.998 \\
\hline & \multirow{3}{*}{ 6th year } & 4 th year & 0.52643 & 0.315 \\
\hline & & 5th year & -0.09203 & 0.993 \\
\hline & & Intern & -0.17857 & 0.984 \\
\hline & \multirow{3}{*}{ Intern } & 4 th year & 0.70500 & 0.373 \\
\hline & & 5 th year & 0.08654 & 0.998 \\
\hline & & 6th year & 0.17857 & 0.984 \\
\hline \multirow{12}{*}{$\begin{array}{l}\text { Score part-4 } \\
\text { (Analgesics) }\end{array}$} & \multirow{3}{*}{4 th year } & 5th year & -0.42077 & 0.497 \\
\hline & & 6th year & -0.61857 & 0.353 \\
\hline & & Intern & -0.94000 & 0.299 \\
\hline & \multirow{3}{*}{ 5th year } & 4 th year & 0.42077 & 0.497 \\
\hline & & 6th year & -0.19780 & 0.963 \\
\hline & & Intern & -0.51923 & 0.790 \\
\hline & \multirow{3}{*}{ 6th year } & 4th year & 0.61857 & 0.353 \\
\hline & & 5th year & 0.19780 & 0.963 \\
\hline & & Intern & -0.32143 & 0.951 \\
\hline & \multirow{3}{*}{ Intern } & 4 th year & 0.94000 & 0.299 \\
\hline & & 5 th year & 0.51923 & 0.790 \\
\hline & & 6th year & 0.32143 & 0.951 \\
\hline \multirow{12}{*}{$\begin{array}{l}\text { Score part-5 } \\
\text { (Sedatives) }\end{array}$} & \multirow{3}{*}{ 4th year } & 5th year & -0.07692 & 0.979 \\
\hline & & 6th year & -0.21429 & 0.815 \\
\hline & & Intern & -0.58333 & 0.342 \\
\hline & \multirow{3}{*}{ 5th year } & 4 th year & 0.07692 & 0.979 \\
\hline & & 6th year & -0.13736 & 0.955 \\
\hline & & Intern & -0.50641 & 0.510 \\
\hline & \multirow{3}{*}{ 6th year } & 4th year & 0.21429 & 0.815 \\
\hline & & 5th year & 0.13736 & 0.955 \\
\hline & & Intern & -0.36905 & 0.784 \\
\hline & \multirow{3}{*}{ Intern } & 4 th year & 0.58333 & 0.342 \\
\hline & & 5 th year & 0.50641 & 0.510 \\
\hline & & 6th year & 0.36905 & 0.784 \\
\hline
\end{tabular}

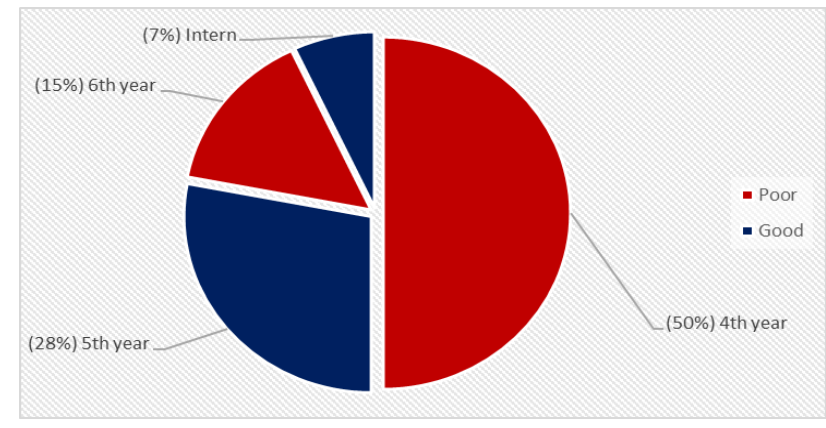

Figure 1: Percentage of overall skills of medications prescription among all students.

Overall knowledge was poor through all levels (Figure $1)$.
The study showed that there was a significant difference in knowledge about part one (antibiotics) between 5th year students in relation to students in the other levels; while there was no significant difference between 4th, 6th year students and interns (Table 1).

For part two (antifungals), there was a significant difference in knowledge between the 4th, 5th year students and intern $(p=0.001)$. But no significant difference between 6th years compared with 4th and 5th year students (Table 1).

While for the third part (antivirals), fourth part (analgesics) and fifth part (sedatives) there was no significant difference in score between all levels (Table $1)$. 
Table 2: Comparison of knowledge overall score between different study levels.

\begin{tabular}{|llllll|}
\hline \multicolumn{7}{|c|}{ ANOVA } \\
\hline Assessment score & df & Mean square & F & P value \\
\hline Between groups & 437.959 & 3 & 145.986 & 14.773 & 0.0001 \\
\hline Within groups & 909.156 & 92 & 9.882 & & \\
\hline Total & 1347.115 & 95 & & & \\
\hline
\end{tabular}

Table 3: Pre and post comparison of knowledge after web-application launching.

\begin{tabular}{|c|c|c|c|c|}
\hline & Question & Pre & Post & P value \\
\hline & \multicolumn{4}{|l|}{ Antibiotics } \\
\hline 1 & Side effect of clindamycin & 45.8 & 48.3 & 0.723 \\
\hline 2 & Amoxicillin allergy alternative & 71.9 & 71.9 & 0.999 \\
\hline 3 & Pregnancy category to tetracycline & 39.6 & 52.8 & 0.061 \\
\hline 4 & Clindamycin is contraindicated in & 51.0 & 53.4 & 0.734 \\
\hline 5 & Metronidazole is used to treat which infection & 42.7 & 42.6 & 0.988 \\
\hline \multirow[t]{2}{*}{6} & Dose of doxycycline for periodontitis & 16.7 & 25.8 & 0.116 \\
\hline & \multicolumn{4}{|l|}{ Antifungal } \\
\hline 7 & Dose of oral suspension of nystatin & 6.3 & 18 & 0.011 \\
\hline 8 & Pregnancy category of ketoconazole & 33.3 & 18 & 0.013 \\
\hline 9 & Relation of omeprazole with ketoconazole & 17.7 & 31.5 & 0.024 \\
\hline 10 & Side effect of clotrimazole & 26.0 & 39.3 & 0.045 \\
\hline \multirow[t]{2}{*}{11} & Increase the action of warfarin & 10.5 & 32.6 & 0.001 \\
\hline & \multicolumn{4}{|l|}{ Antivirals } \\
\hline 12 & Pregnancy category of acyclovir & 35.4 & 38.2 & 0.682 \\
\hline 13 & Antiviral drugs available OTC & 14.6 & 21.3 & 0.218 \\
\hline \multirow[t]{2}{*}{14} & Side effect of acyclovir (Response 1) & 15.6 & 28.1 & 0.011 \\
\hline & Side effect of acyclovir (Response 2) & 26 & 38.2 & 0.065 \\
\hline \multirow[t]{2}{*}{15} & Drug to treat recurrent herpes labials & 18.9 & 30.3 & 0.062 \\
\hline & Analgesics & & & \\
\hline \multirow[t]{2}{*}{16} & NSAIDs contraindicated in (Response 1) & 27.4 & 36.0 & 0.187 \\
\hline & NSAIDs contraindicated in (Response 2) & 53.7 & 57.3 & 0.609 \\
\hline \multirow[t]{2}{*}{17} & Ibuprofen interactions (Response 1) & 22.1 & 40.4 & 0.005 \\
\hline & Ibuprofen interactions (Response 2) & 25.3 & 28.0 & 0.666 \\
\hline 18 & Maximum dose of paracetamol & 33.3 & 70.8 & 0.001 \\
\hline \multirow[t]{2}{*}{19} & Overdose of paracetamol (Response 1) & 16.8 & 30.2 & 0.025 \\
\hline & Overdose of paracetamol (Response 2) & 48.4 & 42.7 & 0.419 \\
\hline 20 & Children dose of paracetamol & 10.4 & 31.5 & 0.002 \\
\hline 21 & Safe analgesic for pregnant women & 69.8 & 58.4 & 0.094 \\
\hline 22 & Dose of diclofenac potassium & 8.3 & 34.8 & \\
\hline \multirow[t]{2}{*}{23} & Ibuprofen contra indication in which trimester & 26.0 & 41.6 & 0.001 \\
\hline & Sedatives & & & \\
\hline \multirow[t]{2}{*}{24} & Nitrous oxide contra indication (Response 1) & 26.3 & 29.2 & 0.649 \\
\hline & Nitrous oxide contra indication (Response 2) & 45.2 & 36 & 0.186 \\
\hline \multirow[t]{2}{*}{25} & Side effects of nitrous oxide (Response 1) & 18.9 & 14.6 & 0.416 \\
\hline & Side effects of nitrous oxide (Response 2) & 23.1 & 24.7 & 0.797 \\
\hline 26 & Dose of diazepam for anxious patients & 15.6 & 20.2 & 0.397 \\
\hline 27 & Dose of midazolam in children & 13.5 & 24.7 & 0.044 \\
\hline
\end{tabular}

When comparing the overall score of the students from the different levels, the study showed a significant difference in knowledge $\mathrm{p}=0.0001$ (Table 2).
Overall, prescription skills among the 5th year students and intern were good compared to their counterpart in the 4th and 6th years (Figure 1). 
Table 4: Effect of web-based application on the knowledge of some drugs used in dental practice

\begin{tabular}{|llll|}
\hline Variables & $\begin{array}{l}\text { Before web-based } \\
\text { application } \\
\text { (Mean score) }\end{array}$ & $\begin{array}{l}\text { After web-based } \\
\text { application } \\
\text { (Mean score) }\end{array}$ & P value \\
\hline Knowledge about antibiotics & 2.6907 & 2.8427 & 0.499 \\
\hline Knowledge about antifungal & 0.9691 & 1.4944 & 0.002 \\
\hline Knowledge about antiviral & 1.0747 & 1.3680 & 0.052 \\
\hline Knowledge about analgesics & 2.5567 & 3.5393 & $<0.001$ \\
\hline Knowledge about sedative agent & 0.8351 & 0.9663 & 0.278 \\
\hline Overall knowledge about therapeutic agents & 8.1366 & 10.2107 & $<0.001$ \\
\hline
\end{tabular}

Table 5: Relation of prescribing medication with knowledge score.

\begin{tabular}{|c|c|c|c|c|c|}
\hline \multicolumn{2}{|c|}{ What do your rely when prescribe } & Number & Mean & \multicolumn{2}{|c|}{ Std. deviation } \\
\hline \multicolumn{2}{|c|}{ Your knowledge } & 26 & 5.7596 & \multicolumn{2}{|c|}{3.64450} \\
\hline \multicolumn{2}{|c|}{ Your supervisor } & 44 & 9.9602 & \multicolumn{2}{|c|}{3.58288} \\
\hline \multicolumn{2}{|c|}{ Medical dictionaries } & 19 & 7.0789 & \multicolumn{2}{|c|}{2.76392} \\
\hline \multicolumn{2}{|c|}{ Class mates } & 3 & 7.5000 & \multicolumn{2}{|c|}{1.63936} \\
\hline \multicolumn{2}{|l|}{ Others } & 4 & 7.5000 & \multicolumn{2}{|c|}{1.04083} \\
\hline \multicolumn{2}{|l|}{ Total } & 96 & 8.0729 & \multicolumn{2}{|c|}{3.76565} \\
\hline \multicolumn{6}{|l|}{ Assessment score } \\
\hline & Sum of squares & df & Mean square & $\mathrm{F}$ & $\mathrm{P}$ value \\
\hline Between groups & 316.930 & 4 & 79.233 & 6.999 & 0.0001 \\
\hline Within groups & 1030.185 & 91 & 11.321 & & \\
\hline Total & 1347.115 & 95 & & & \\
\hline
\end{tabular}

Table 6: Overall satisfaction about the online application.

\begin{tabular}{|c|c|c|c|}
\hline Variables & & Frequency (N) & Percentage $(\%)$ \\
\hline \multirow{3}{*}{ How did you find the information provided? } & Very helpful & 43 & 62.3 \\
\hline & Not helpful & 8 & 11.6 \\
\hline & I can't tell & 18 & 26.1 \\
\hline \multirow{3}{*}{ How would you rate the application? } & User Friendly & 33 & 47.8 \\
\hline & Complicated & 12 & 17.4 \\
\hline & Neutral & 24 & 34.8 \\
\hline \multirow{4}{*}{ Would you use it as study guide? } & Yes & 38 & 55.1 \\
\hline & No & 7 & 10.1 \\
\hline & May be & 13 & 18.8 \\
\hline & I do not know & 11 & 15.9 \\
\hline \multirow{4}{*}{ Would you refer to it in prescribing drugs? } & Yes & 37 & 53.6 \\
\hline & No & 10 & 14.5 \\
\hline & May be & 10 & 14.5 \\
\hline & I do not know & 12 & 17.4 \\
\hline \multirow{4}{*}{ Would you recommend to your colleagues? } & Yes & 44 & 63.7 \\
\hline & No & 3 & 4.3 \\
\hline & May be & 16 & 23.2 \\
\hline & I do not know & 6 & 8.7 \\
\hline
\end{tabular}

Results after launching the web-application showed that there was an improvement in knowledge as per question, part and the overall score (Table 3). T-test analysis showed that this change was not statistically different in all sections (Table 4).
We asked the students some questions about the application to assess their satisfaction and opinions. Of all participants $62.2 \%$ found it very helpful, $47.8 \%$ found it easy and user friendly and $55.1 \%$ said that they would definitely use it as a study guide. Also half of the study sample $(53.6 \%)$ said that they would refer to it when prescribing medications for their patients and $63.7 \%$ 
agreed that they would recommend their colleagues in and outside the university to use it (Table 6).

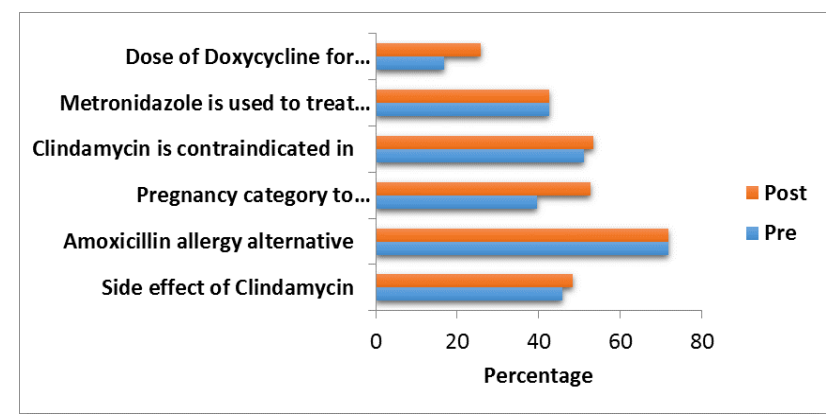

Figure 2: Antibiotics knowledge.

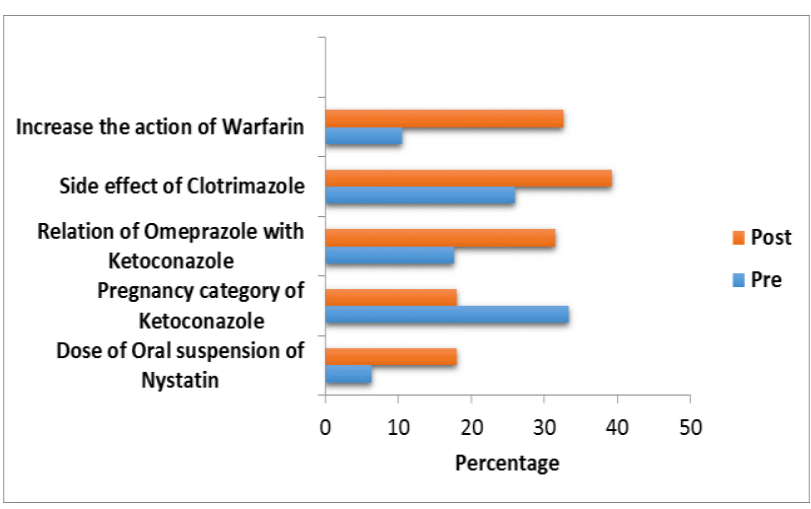

Figure 3: Knowledge about antifungal drugs.

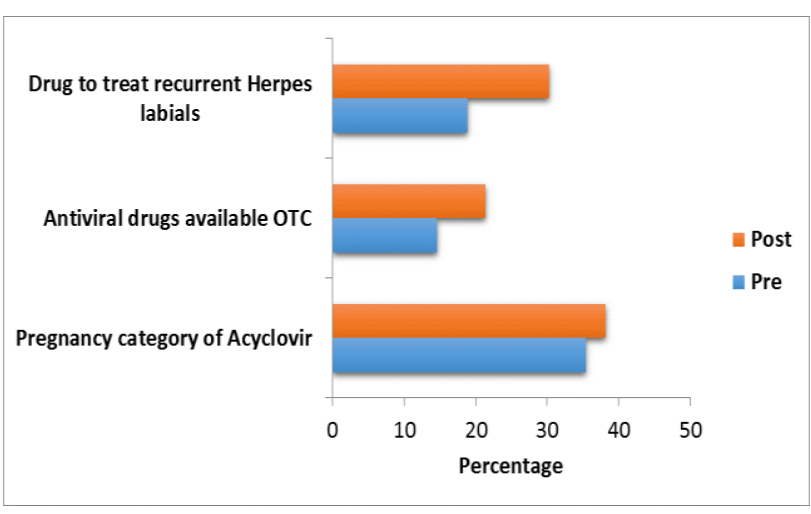

Figure 4: Knowledge about antiviral drugs.

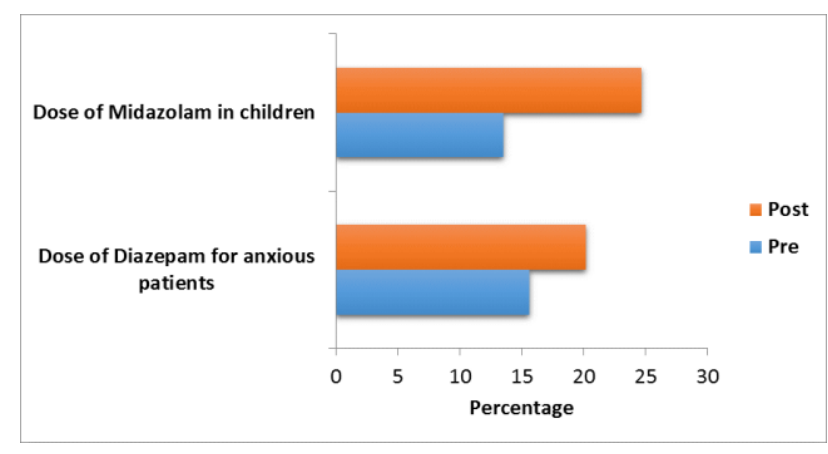

Figure 5: Knowledge about sedative agents.

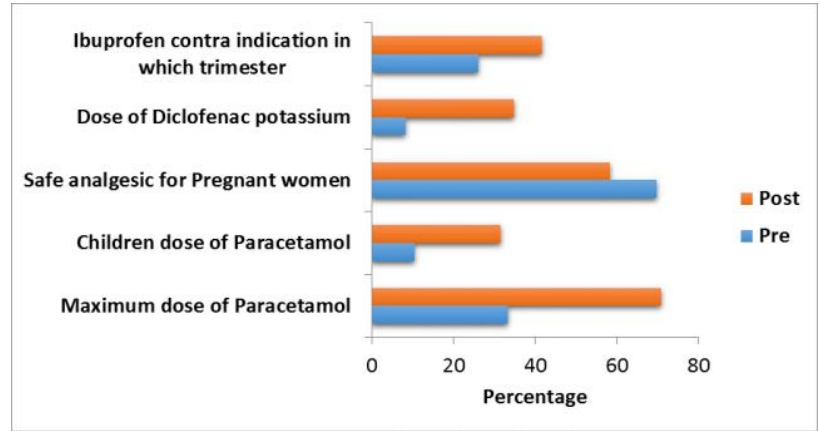

Figure 6: Knowledge about analgesics.

\section{DISCUSSION}

This study was conducted to assess prescribing skills among dental students and to evaluate the efficacy of an online application in improving their skills. Lacking the knowledge and prescribing skills of drugs is a common problem among medical and dental students as documented by many studies. ${ }^{1-4}$

Data from the first questionnaire (phase I) showed that students had poor skills and insufficient information when it comes to prescribing medications for their patients; in line to most studies carried in the same area. ${ }^{1-}$

The study was planning to assess if being taught by different specialty would make a difference; unfortunately, this variable was neglected as all courses were taught by pharmacists.

Students showed better knowledge when it comes to antibiotics and analgesics in both pre and post phases with mean values $(2.6907,2.8427)$ and $(2.5567,3.5393)$ respectively. This can be due to them being the most common medications prescribed by all specialties while antivirals and/or antifungals are prescribed mainly by oral surgeons and oral medicine specialist.

The weakest area in antibiotics knowledge was knowing the actual drug dose (Figure 2), similar to what was reported by Guzman Alvarez and colleagues 2012 as he found that the most common error reported by dental students was lack of knowledge about posology. ${ }^{1}$ Again we found that only $16.7 \%$ of the participants are aware of Paracetamol overdose and its complications. Another agreement with their study we found about (45.8\%) of the students depend on their supervisors in clinics to prescribe medication for patients.

In the current study, interns showed poor knowledge in prescribing drugs (Figure 1) somewhat similar to findings of Wali et al were the majority of the interns lacked knowledge in prescribing basic drugs used in dentistry. ${ }^{9}$

When investigating the relation between students' knowledge and their study level there was a statistically 
significance difference between 5th year students compared to 4th, 6th and interns ( $>00.05)$; in contradiction to the findings of Moura et al, who found that knowledge improve as the year level increase. ${ }^{10} \mathrm{~A}$ reasonable explanation in our case can be due to 5 th year students taking the course during the study period. While 4th year haven't taken the second pharmacology course and most probably 6th year and interns had forgotten the information they were taught.

Engaging technology in learning process has proven its efficacy worldwide in facilitating students' learning. ${ }^{11,12}$

In line with this trend we found that data collected after the online-application showed significant improvement in students' knowledge (Table 3) supported by the findings of Akram et al that using multiple strategies in teaching pharmacology course/s proved its efficiency in improving students' knowledge. ${ }^{13}$

This is the first study to be carried in the kingdom investigating this area. The application allowed the students to quickly access to a lot of information such as the brand names in KSA, indications, contraindications, serious interactions between medications and maximum dosage of these medications which helps the students while writing prescriptions. The ability to use this application without the need of having an internet connection increased the benefit of it and made it more accessible and user friendly.

Nevertheless, the period of using phone application by the students was not quite enough to have a remarkable impact on the information they have as the team anticipated. The number of female students who participated in the study was too small that led us to neglect an important predicator of knowledge that is gender differences.

As a new area of research still further investigations are needed. Including students from other universities will give a bigger and clearer picture and will allow better comparisons. Using technology should be a part of courses that need memorization such as "pharmacology" to help in enhancing students' retention.

Prescribing medications skills are really important in our practice as we know, that is due to their serious impact on the quality and success of the treatment. The teaching strategies that are currently widely used to deliver this science are proven to be not effective as shown by previous researches. With that in mind, new methods should be implemented to improve students' knowledge and skills.

\section{ACKNOWLEDGEMENTS}

Special thanks to Dr. Hatem M Abuohashish, Lecturer of Pharmacology-Department of Biomedical Dental
Sciences (CoD-UoD) and to the IT Department in the University.

Funding: No funding sources

Conflict of interest: None declared

Ethical approval: Not required

\section{REFERENCES}

1. Guzmán-Álvarez R, Medeiros M, Lagunes LIR, Campos-Sepúlveda AE. Knowledge of drug prescription in dentistry students. Drug, Healthcare and Patient Safety. 2012;4:55-9.

2. Mendonca JM, Lyra DP Jr., Rabelo JS, Siqueira JS, Balisa-Rocha BJ, Gimenes FR, et al. Analysis and detection of dental prescribing errors at primary health care units in Brazil. PWS. 2010;32(1):30-5.

3. Teresa Espinosa-Meléndez M. An Evaluation of the Pharmacological Knowledge of Undergraduate and Graduate Students at UNAM'S Faculty of Dentistry; 2006.

4. Rauniar GP, Roy RK, Das BP, Bhandari G, Bhattacharya SK. Prescription writing skills of preclinical medical and dental undergraduate students. JNMA. 2008;47(172):197-200.

5. Inappropriate prescribing. Available at: http://www.apa.org. Accessed on 3 June 2018.

6. Aronson JK. A prescription for better prescribing. British J Clin Pharmacol. 2006;61(5):487-91.

7. Yagiela JA, Dowd FJ, Mariotti A, Neidle EA. Pharmacology and Therapeutics for Dentistry - EBook: Elsevier Health Sciences; 2010.

8. Dentdrug. Available at: https://play.google.com/ store/apps/details?id=sa.edu.ud.dentdrug. Accessed on 3 June 2018.

9. Wali A, Ali A, Siddiqui TM, Jafri H. Assessing Prescription Writing Skills of House Officers in Dental Teaching Hospitals of Karachi, Pakistan. 2012: 294-296.

10. de Moura CS, Naves JOS, Coelho EB, Lia EN. Assessment of quality of prescription by dental students. J Applied Oral Sci. 2014;22(3):204-8.

11. Hew KF, Cheung WS. Use of Web 2.0 technologies in K-12 and higher education: The search for evidence-based practice. Edu Res Rev. 2013;9:4764.

12. Kamarudin G, Penm J, Chaar B, Moles R. Educational interventions to improve prescribing competency: a systematic review. BMJ open 2013;3(8):e003291.

13. Akram A, Zamzam R, Mohamad NB, Abdullah D, Meerah SM. An assessment of the prescribing skills of undergraduate dental students in Malaysia. J Dent Educ. 2012;76(11):1527-31.

Cite this article as: Alali HA, Alali HA, Alghamdi AA, Ali AIA, Alkhalaf AH, Jaffar B. An assessment of prescribing skills among dental students in the eastern province, Saudi Arabia, University of Dammam. Int J Community Med Public Health 2018;5:4175-82. 